\title{
Docência na educação de mulheres jovens, adultas e idosas no cárcere ${ }^{1}$
}

\author{
Ivanilde Apoluceno de Oliveira ${ }^{2}$ \\ Suzianne Silva de Oliveira ${ }^{3}$
}

\begin{abstract}
Resumo
Neste artigo apresenta-se o recorte de uma pesquisa qualitativa, concluída em 2017, sobre a educação de mulheres jovens, adultas e idosas em um Centro de Reeducação Feminino, na cidade de Belém do Pará. O objetivo é analisar a educação no cárcere, com o foco para a docência e as questões feministas. Consiste em um estudo de caso. As participantes são: duas coordenadoras pedagógicas, duas professoras e três egressas do Centro de Reeducação (CRF). Os procedimentos foram o levantamento bibliográfico e documental, a pesquisa exploratória e entrevistas semiestruturadas. A sistematização e análise foram realizadas por meio de categorizações temáticas. Entre os resultados aponta-se que na docência no cárcere feminino é necessário desenvolver uma prática docente dialógica e crítica.
\end{abstract}

Palavras-chave: Docência; Educação de Jovens, Adultos e Idosos; Presidio Feminino; Educação no Cárcere.

\section{Teaching in the education of young, adult and elderly women in prison}

\begin{abstract}
This article presents the clipping of a qualitative research, completed in 2017, on the education of young, adult and elderly women in a Women's Reeducation Center, in the city of Belém do Pará. The objective is to analyze prison education, with the focus for teaching and feminist issues. It consists of a case study. The participants are: two pedagogical coordinators, two teachers and three graduates of the Reeducation Center (CRF). The procedures were bibliographic and documentary survey, exploratory research and semi-structured interviews. Systematization and analysis were performed through thematic categorizations. Among the results, it is pointed out that in female prison teaching it is necessary to develop a dialogical and critical teaching practice.

Keywords: Teaching Youth, Adult and Elderly Education; Female Presidio; Prison Education.
\end{abstract}

\section{Introdução}

Neste artigo apresenta-se o recorte de uma pesquisa de campo qualitativa, concluída em 2017, sobre a educação de mulheres jovens, adultas e idosas em um Centro de Reeducação Feminino do Estado do Pará, localizado na cidade de Belém. Trata-se de uma pesquisa oriunda de uma dissertação de mestrado.

O objetivo é analisar a docência da Educação de Jovens, Adultos e Idosos - EJA no cárcere

\footnotetext{
${ }^{1}$ Financiamento do CNPq

${ }^{2}$ Instituição, cidade e endereço eletrônico

${ }^{3}$ Instituição, cidade e endereço eletrônico
} 
feminino, refletindo sobre a concepção e prática pedagógica, a cultura prisional masculina vigente no cárcere feminino, bem como o significado e a importância da educação em escola prisional. O foco deste estudo é para a docência e para as questões feministas presentes no processo educacional da EJA com mulheres.

A educação carcerária feminina apresenta como público mulheres que são marginalizadas e estigmatizadas na sociedade, por questões de gênero, classe, etnia, escolarização e idade, as quais precisam ser refletidas e debatidas no contexto educacional, na medida em que a maioria é pobre, negra, de baixa escolarização e jovem. Além disso, as prisões apresentam cultura e práticas prisionais masculinas, que invisibilizam as mulheres e silencia o "ser mulher", não atendendo as suas especificidades femininas, situações que precisam ser problematizadas quando se analisa a educação no cárcere.

A educação no sistema prisional é garantida na legislação brasileira, mas é importante que se investigue que tipo de educação está sendo efetivada e como a docência se apresenta neste contexto, sua relevância social, dificuldades e desafios.

Assim, neste artigo apresenta-se, inicialmente, o caminhar metodológico da pesquisa, seguido do debate sobre a cultura prisional masculina vigente no cárcere feminino no Brasil e a educação de mulheres jovens, adultas e idosas em privação de liberdade, direcionando o olhar para a docência e as questões femininas inerentes a esta educação.

\section{O caminhar metodológico da pesquisa}

Os dados apresentados neste artigo têm por base uma pesquisa de campo qualitativa realizada em um Centro de Reeducação Feminino (CRF), na cidade de Belém do Pará, concluída em 2017.

Na pesquisa qualitativa, segundo Lüdke e André (1986), “o interesse do pesquisador ao estudar determinado problema é verificar como ele se manifesta nas atividades, nos procedimentos e nas interações cotidianas" (p.12). Além disso, "o 'significado' que as pessoas dão às coisas e a sua vida são focos de atenção especial pelo pesquisador" (p.12). Trata-se, ainda, de um estudo de caso, que se caracteriza como um caso único, "particular, distinto de outros, mesmo que posteriormente venham a ficar evidentes certas semelhanças com outros casos ou 
situações" (p.17).

O caso analisado, neste estudo, é a docência realizada na Educação de Jovens, Adultos e Idosos do Centro de Reeducação Feminino, lócus da investigação, localizado na cidade de Belém do Pará.

As participantes da pesquisa foram: duas coordenadoras pedagógicas, duas professoras que atuam na EJA no ensino fundamental e três egressas do Centro de Reeducação Feminino, com o seguinte perfil: as coordenadoras pedagógicas apresentam a faixa etária de 45 e 50 anos, uma é pedagoga e a outra licenciada em Educação de Jovens e Adultos em privação de liberdade; uma possui 10 anos e outra 5 meses de trabalho na educação no cárcere. As professoras estão na faixa etária de 44 e 50 anos, possuem qualificação em nível de especialização e mestrado; uma tem 7 e outra 6 anos de magistério na escola do cárcere. As egressas apresentam a faixa etária de 31, 40 e 51 anos, de cor morena, parda e negra e todas são solteiras e com filhos (OLIVEIRA, 2017). Todas estão mencionadas neste estudo por meio de suas funções e letras $A, B, C .$.

Os procedimentos metodológicos utilizados foram o levantamento bibliográfico e documental, a realização de pesquisa exploratória e de entrevistas semiestruturadas com as participantes da pesquisa. A sistematização e a análise foram realizadas por meio de categorias temáticas, com base em técnicas da Análise de Conteúdo de Bardin (1979).

Segundo Oliveira e Mota Neto (2011, p.164), as categorias temáticas "são fatores, aspectos, elementos do fato ou situação em estudo que são classificados e reunidos em eixos ou unidades temáticas a partir e com os dados coletados". As categorias temáticas construídas possibilitaram a organização dos itens e subitens do texto deste artigo.

Como cuidado ético foi utilizado o Termo de Compromisso Livre e Esclarecido (TCLE) que foi assinado pelas participantes, autorizando a gravação em áudio, o registro fotográfico, e, ainda a utilização dos resultados desta pesquisa para fins acadêmicos.

\section{O cárcere feminino no Brasil: cultura prisional masculina}

O sistema prisional foi criado com o objetivo de punir pessoas pelas práticas de determinados crimes. Agrega uma cultura prisional como mecanismo de correção e disciplina da pessoa presa, homem e mulher, que segundo Goffman (1961) envolvem rotinas, regras, 
autoritarismo, disciplina, violência, controle, entre outros.

A cultura prisional implica na internalização de hábitos, gestos, costumes, códigos e modos de pensar, que influenciam na forma como as pessoas em privação de liberdade vão formar sua conduta, personalidade, modos de agir e de pensar (VASQUEZ, 2008).

Essa cultura prisional constitui-se como masculina, porque, historicamente, a reclusão de mulheres interessava aos homens, pais e maridos. A custódia da mulher configurava-se na Idade Média em uma correção, justificada pela manutenção de sua submissão ao homem, o qual era dotado de direito e autonomia sobre a mulher. Assim, "as primeiras instituições prisionais, a reclusão (muitas vezes perpétua) sempre foi uma realidade, no contexto de uma política de correção que oscilava entre a casa e o convento" (MENDES, 2014, p.140).

Desta forma, o contexto atual das prisões representa desdobramentos da forma como se compreendia e se punia a mulher no passado histórico (OLIVEIRA, 2017), isto é, com base nos preceitos patriarcais, legitimando as relações de poder entre o homem e a mulher, mantendo-se nos presídios femininos a lógica de pensar e de organização masculina, cuja consequência, é a ausência de políticas públicas destinadas às mulheres e suas especificidades identitárias femininas.

Oliveira (2017) explica que apesar de Lemos Brito, em 1924, ter proposto a construção de um reformatório direcionado ao tratamento específico para a mulher, por parte do Sistema Penitenciário, ainda permanece a desigualdade entre os presídios de mulheres e os de homens, sendo mantidas as mesmas estruturas básicas das prisões masculinas.

Colares e Chies (2010) consideram que a prisão é masculina em sua estrutura e masculinizante em suas práticas. Por isso, os presídios femininos são demarcados pelo improviso, sem o mínimo de condições físicas, estruturais e de gestão para atender de forma digna e mais humana as mulheres que estão em privação de liberdade.

Destaca Oliveira (2017) que a mulher, ao ingressar no sistema prisional, pensado para homens, é obrigada a adotar novos comportamentos a fim de enquadrar-se neste "novo" contexto. Em consequência, o "ser mulher" é silenciado, uma vez que, o encarceramento masculinizante exige o abandono e/ou transformação de sua essência feminina pela sujeição a um ambiente que não foi pensado nem mesmo adaptado a elas.

Ressalta-se que no Brasil vem crescendo o número de mulheres encarceradas. Houve um salto nos anos de 2005 para 2016 de 12.925 para 44.721. As mulheres representam $5,8 \%$ de toda 
a população carcerária brasileira (MERELES, 2017; PONTES; MARTINS, 2017).

Do total de mulheres presas, $80 \%$ são mães e principais responsáveis pelos cuidados dos filhos, que geram outros problemas sociais, bem como, nem todos os presídios possuem estrutura apropriada para que cuidem e amamentem seus filhos. $60 \%$ estão encarceradas por crimes relacionados ao tráfico de drogas, porque servem de transportadoras para atender aos companheiros (AILANDA, 2017; PONTES; MARTINS, 2017).

Além da questão de gênero, a reclusão das mulheres também está associada às questões de etnia, idade e de classe. A maioria das mulheres privadas de liberdade é negra (68\%) e pertencente às classes populares e um número significativo é jovem (50\% têm entre 18 e 29 anos), fatores estes que refletem no nível baixo de sua escolaridade (AILANDA, 2017). A pesquisa revelou que um número significativo de mulheres privadas de liberdade não frequenta a escola prisional, porque não percebe a importância da escolarização. A indução maior de participação na escola prisional é a possibilidade da redução da pena. A população carcerária de mulheres no Pará é correspondente a 730 e destas, 436 (59,5\%) estudam e 294 (40,5\%) não possuem acesso à escolarização (PARÁ, 2015 apud OLIVEIRA, 2017).

Oliveira (2017) informa que a evasão escolar é muito recorrente na escola prisional existindo turmas com menos de dez alunas. A procura pela educação no início do ano é grande por conta da remissão, aprendizagem e ocupação do tempo, contudo, no decorrer do processo essas mulheres vão abandonando as salas de aula, principalmente pelo ensino escolar tradicional, que não se apresenta como atrativo para elas. Este ensino pelo seu caráter conteudista, racionalista e meritocrático não motiva a participação das mulheres em privação de liberdade.

A educação para mulheres jovens, adultas e idosas privadas de liberdade, então, se apresenta como uma necessidade social, sendo garantida na legislação brasileira, influenciada por documentos internacionais, entre os quais a Declaração de Hamburgo aprovada na 5a Conferência Internacional sobre Educação de Jovens e Adultos - V CONFINTEA (1997) e que garantem os direitos das pessoas encarceradas como parte do direito à EJA.

Entre os documentos da legislação brasileira, destaca-se o Projeto “Educando para a Liberdade", de 2005, desenvolvido pelo MEC em parceria da UNESCO, com vistas ao acesso igualitário de toda a população carcerária à educação (BRASIL, 2006) e as Diretrizes Nacionais para educação no sistema prisional (BRASIL, 2009), que estabelece as normas para a oferta de 
Educação para jovens, adultos e idosos, em situação de privação de liberdade.

Entretanto, apesar de a educação estar garantida na legislação brasileira, precisa ser analisada que tipo de educação está sendo efetivada no sistema carcerário, se é a que reproduz a mentalidade colonial da submissão às regras masculinas da sociedade, visando à manutenção do status quo ou é a que promove a formação humana, possibilite um processo de escolarização com qualidade, com vistas a sua inclusão social. Isto é, uma educação contrária à que padroniza o sistema fazendo da escola prisional um aparelho reprodutor da subordinação, domesticação e docilidade dos sujeitos aprisionados, na perspectiva de Foucault (OLIVEIRA, 2017).

Pereira (2011, p.46) estabelece a distinção entre a educação do cárcere e a educação no cárcere (grifos nossos).

A educação do cárcere é conceituada como:

[...] práticas adaptativas que se processam dentro das prisões para que o preso adquira a cultura e ética carcerárias - aceite as regras e visão de mundo desse espaço, exerçam a submissão e aprenda a lidar com questões que eles não estão preparados, mesmo que seja à base da violência física.

E a educação no cárcere como a que possibilita:

acessar conhecimentos para aquelas pessoas que estão presas, desenvolvendoas cognitiva e socialmente para que possam se reintegrar à sociedade. Essa educação é tanto para a sua escolarização (formação dentro do sistema oficial de ensino) e profissionalização (formação para o mundo do trabalho).

Considera-se que a educação no cárcere precisa além da escolarização e da formação para o trabalho, promover o empoderamento das mulheres refletindo criticamente sobre sua situação de gênero, como pessoa e cidadã e lhes permitam "chegar a ser sujeitos, construir-se como pessoa, transformar o mundo, estabelecer com [as outras e] os outros, relações de reciprocidade, fazer a cultura e a história" (FREIRE, 2005, p.53).

\section{O centro de reeducação feminino do Pará: criação e estrutura físico-educacional}

O Centro de Reeducação Feminino foi criado legalmente em 1993 e implantado em 1998, na cidade de Belém do Pará, visando atender mulheres custodiadas no regime semiaberto, 


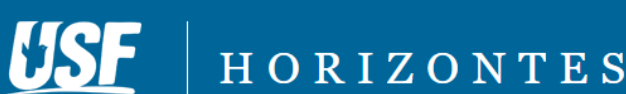

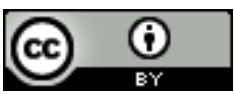

ARTIGO

DOI: https://doi.org/10.24933/horizontes.v36i2

fechado e provisório.

O Centro de Reeducação Feminino do Pará possui 04 blocos de edificações, nos quais as mulheres são separadas, conforme o regime de enquadramento. Cada bloco possui um total de 20 celas fechadas por grades e cada cela possui um banheiro e um tanque para lavar roupa, cuja capacidade é para 12 mulheres, o que aponta para a situação de superlotação. Próximo e vinculado ao Centro foi criada, em 2013, uma Unidade Materno Infantil (UMI) destinada a atender as internas grávidas, que permanecem neste local do nascimento do bebê ao seu primeiro ano de vida. Esta Unidade dispõe de 14 leitos (OLIVEIRA, 2017).

Com vistas ao processo de escolarização das mulheres em privação de liberdade, o Centro possui a seguinte infraestrutura: quatro salas de aula, uma biblioteca, uma sala de arquivo, uma sala da coordenação pedagógica, dois banheiros, um refeitório e um salão para atividades coletivas.

As salas de aula apresentam uma boa estrutura física, sendo as mesas e carteiras confortáveis e o quadro e as paredes apresentam pintura bem conservada. A biblioteca, também, apresenta uma boa estrutura física e um acervo diversificado. Entretanto, há precariedade na área de lazer, pois faltam iluminação e pintura, bem como há necessidade de reforma dos banheiros. Não há sala de professores (OLIVEIRA, 2017).

Figura 1 - Sala de aula e da biblioteca

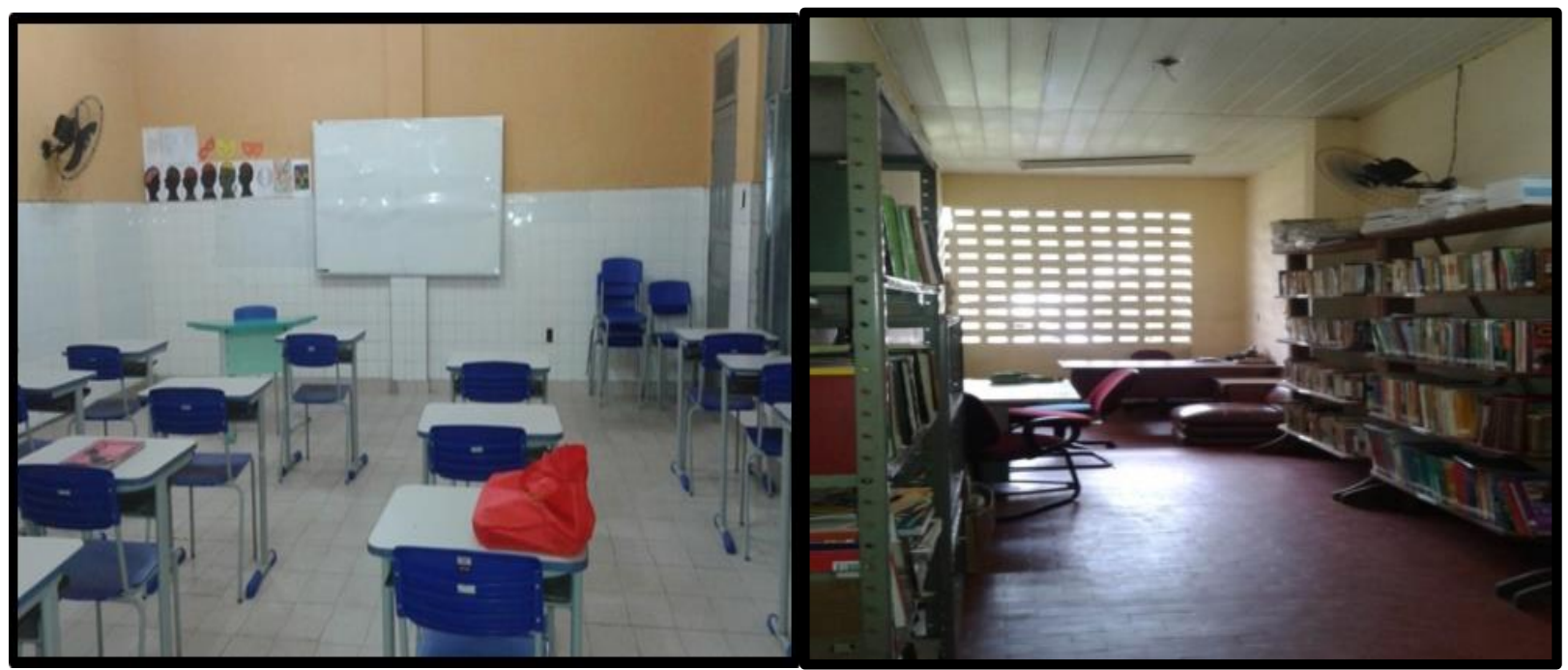

Fontes: Arquivo de Oliveira (2017, p.107-108).

Periódico Horizontes - USF - Itatiba, SP - Brasil - e020060 
Oliveira (2017) explica que as turmas da Educação de Jovens e adultos são ofertadas, nos três turnos, por meio de convênio celebrado entre a Secretaria Estadual de Educação do Estado do Pará - SEDUC e a Superintendência do Sistema penitenciário do estado do Pará - SUSIPE. Vinculados à EJA são ofertados ainda cursos profissionalizantes pelo SENAI e SENAC, cursos livres de música, pintura, cooperativa, entre outros. Há, também, alguns projetos: "Tempo de ler", "Movimento de Alfabetização" (MOVA) e o "Programa Brasil Alfabetizado" que estão direcionados à alfabetização de adultos, com vistas a superar o analfabetismo e a evasão escolar. Já o Projeto "Tempo de Ver" dispõe de óculos para as mulheres com problemas de visão.

\section{O projeto político-pedagógico da unidade prisional feminina}

O Projeto Político Pedagógico da unidade prisional feminina proposto para o período (2015-2016) encontrava-se, em 2016, na cidade de Brasília, para análise e possíveis reajustes. Entretanto, as metas para o plano de ação educacional do Centro de Reeducação Feminino do Pará nestes dois anos foram: (1) a garantia de acompanhamento técnico pedagógico para professores e reeducandas, através da efetivação do convênio SEDCUC/SUSIPE como política pública de garantia de direitos a pessoa privada de liberdade; (2) a continuidade dos estudos para os anos subsequentes.

A Coordenadora B e a Professora A esclarecem sobre o Projeto Pedagógico da EJA no cárcere que:

Nós temos um Projeto Pedagógico que a SEDUC diz que tem [...]. Na verdade, é o Projeto da EJA que é adaptado para o prisional. Ele não é um Projeto exclusivamente do cárcere. É nós aqui da unidade, nós criamos, elaboramos um Projeto Pedagógico aqui do CRF que a gente vai falar sobre o étnico racial. Então, esse projeto a gente pretende trabalhar nesse ano de 2016 e ter uma culminância dele no dia da consciência negra. Então a gente criou todo esse projeto praticamente, na verdade foi a Lindomar que criou todo o projeto, ela pensou, ela criou, ela construiu, então a gente está tentando trabalhar eu já mostrei pra alguns professores, a L. já mostrou eles se interessaram, gostaram da temática, querem tentar incluir no plano deles, no planejamento deles, então a gente, pelo menos com quem a gente já conversou eles aceitaram de trabalhar junto, inclusive, o pessoal da remissão pela leitura, eu falei com eles ontem e eles gostaram da ideia eles querem(COORDENADORA B). 
Olha, a gente anda lutando há muito tempo já com essa história, de há! O Projeto Político pedagógico das unidades já estão se fazendo. A não sei quanto tempo. Então, a gente não segue um projeto específico da casa. A gente tem seguido... Por exemplo, atualmente a gente está seguindo pelo menos um tema transversal, nós todos estamos trabalhando agora que é a questão étnico-racial. Então, a gente está seguindo um projeto para todos agora, a gente recebeu e tal as diretrizes do projeto para seguir e, fora a questão do projeto político pedagógico, parece aquele currículo que está sempre em formação e nunca se faz. Então no fundo acaba que a gente não segue direito. A gente se reúne de vez em quando, mas acaba falando... Tentando falar mais ou menos a mesma língua (PROFESSORA A).

Assim, apesar do Projeto Político Pedagógico da unidade prisional feminina estar em fase de tramitação, os professores buscam seguir o plano de ação proposto pela coordenação pedagógica, realizado por meio de um tema gerador anual. Porém, os docentes ressaltam a falta do projeto pedagógico na escola prisional, o que contribui para que desenvolvam um trabalho direcionado à sua unidade prática de ensino (língua portuguesa ou matemática ou sociologia etc.). Com isto, não se estabelece diálogo entre as disciplinas e, por conseguinte não se trabalha na perspectiva curricular interdisciplinar.

\section{A docência no cárcere feminino do estado do Pará}

A concepção de educação que norteia a prática da EJA no Centro, conforme duas coordenadoras pedagógicas é a de Paulo Freire.

A concepção [...] freireana, educação libertadora, emancipadora mesmo, de trabalhar esse sujeito com todo o conhecimento que ele tem de mundo, de vivência, de experiências boas ou más, traumatizantes ou não e, buscar essa transformação na vida dessa pessoa. (COORDENADORA A).

Olha, a concepção educacional é a educação Paulo Freire, freireana no caso. Então, que trata do tema gerador, então essa é a educação, pelo menos teoricamente [...]. Eu não sei ti confirmar se isso exatamente acontece, mas que é essa que está norteando é. (COORDENADORA B).

A educação de Paulo Freire é de fundamental importância para a Educação de Jovens e Adultos no sistema prisional de ensino, pelo seu caráter humanista e ético-político. A educação freireana visa à humanização de homens e mulheres ao denunciar os processos de opressão 
social e de desigualdades sociais e anunciar uma pedagogia do diálogo, do respeito ético à diversidade sociocultural e à valorização da pessoa humana no processo educacional.

Entretanto, a Coordenadora B, não tem certeza se de fato esta educação ocorre na prática no Centro e acrescenta que: "a gente não tem nenhuma concepção que seja exclusivamente para a mulher, para o cárcere e, principalmente para a mulher, então a gente adequa". A coordenadora, então, tem dúvidas se a prática freireana de fato acontece na escola prisional.

Para Freire (1993a, p.68): "a discriminação da mulher, expressada e feita pelo discurso machista e encarnada em práticas concretas é uma forma colonial de tratá-la, incompatível, portanto, com qualquer posição progressista, de mulher ou de homem, pouco importa".

Essa incerteza aparece também na fala da professora A ao não saber identificar qual a concepção que norteia sua prática pedagógica.

A gente não tem essa coisa, de, de há! Nós temos essa concepção! Não, a gente foi com aquela formação inicial né, a gente foi entendendo que era diferenciado né, que o público era diferenciado e, algumas coisas a gente via para o lado de lá, e outras a gente acaba trabalhando as concepções que sempre conheceu né, de formação, a gente vai acrescentando, incorporando, eu quero dizer, o que vai aprendendo, lendo uma coisa aqui, lendo uma coisa ali, em relação à parte didática, mas não tem uma concepção ' $X$ ' pra seguir (PROFESSORA A).

Porém, a educação no cárcere é vista pelas educadoras em uma perspectiva humanista e política, que vai além do processo de escolarização.

A educação no cárcere exige muito o cunho social, é trabalhar com esse ser humano na construção/reconstrução dos sonhos, de ideais, de valores, então, o que significa trabalhar é de estar investindo nessa transformação dessa pessoa (COORDENADORA, A).

Então, é uma responsabilidade muito grande, é uma responsabilidade que ela, ela, ela é além da sala de aula, além da educação. (COORDENADORA, B).

A grande maioria que está aqui dentro não passou por uma educação suficiente para impedir que ele fosse por esse caminho. Então, ai você vai ver que a escolaridade está super ligada à questão da criminalidade. Então, eu me sinto assim, alguém que está remendando para pouquinhos, infelizmente, para muitos pouquinhos [...]. Se a gente for ver o tamanho do cárcere para o tamanho da escola, ela deveria ser maior, eu me sinto uma remendadora de alguns casinhos só. (PROFESSORA, A). 
As educadoras têm a consciência da necessidade social da educação no cárcere e que esta apresenta um caráter de transformação social, já que a falta do acesso à escolarização está associada ao processo de marginalização social.

Do ponto de vista metodológico na EJA são utilizados temas geradores, que são "temas de caráter universal, contidos na unidade epocal mais ampla, que abarca toda uma gama de unidades e subunidades, continentais, regionais, nacionais, etc., diversificadas entre si" (FREIRE, 1987, p.54).

Esses temas geradores, na perspectiva freireana, têm origem na realidade social das mulheres, a partir de suas vivências históricas e sociais e deveriam ser escolhidos pelos docentes. Entretanto, os temas geradores não são escolhidos pelos docentes e sim pela coordenação pedagógica, um por ano, e proposto aos professores, que decidem inseri-lo ou não em seu planejamento pedagógico. O tema proposto pela coordenadora foi o étnico-racial, porque "contribuirá para combater o racismo e o preconceito" (COORDENADORA A).

A coordenação pedagógica da escola prisional do CRF, então, elege a cada ano letivo uma temática central como enfoque para ser trabalhado em todas as disciplinas. A temática escolhida, em 2016, foi a étnico-racial, considerando o número significativo de mulheres negras no cárcere, e embasada pelo slogan "a década do afrodescendente" lançado pela UNESCO, no período de janeiro de 2015 a dezembro de 2024.

Desta forma, o tema proposto pela Coordenação Pedagógica tem como finalidade abordar as questões étnico-raciais em todas as disciplinas e em todas as etapas, visando promover atividades extracurriculares, contemplando um debate importante para a realidade destas mulheres, enquanto afirmação de suas origens étnicas, raciais e culturais.

Não se nega a importância do tema escolhido pela coordenação, ao envolver um trabalho de conscientização, inserção social, respeito, igualdade social, e afirmação de direitos. Porém, considera-se que a escolha deveria ser feita em planejamento conjunto entre professores e coordenação, para que não se desencadeiem práticas pedagógicas independentes sem um plano comum de ação entre os docentes.

Além disso, há a necessidade de diálogo na definição dos temas geradores e a criação de oportunidades aos professores, por parte dos órgãos gestores, a fim de possibilitar trocas de ideias, e novas experiências, para que o trabalho seja realizado de forma inovadora e conjunta. 
À coordenação, também, cabe o papel de dialogar e acompanhar o professor no seu planejamento no processo ensino-aprendizagem, para que haja uma constante reflexão sobre a prática.

O tema proposto pela coordenação é visto pelos participantes da pesquisa como um plano de trabalho educacional, quando de fato se configura em uma estratégia metodológica. $\mathrm{O}$ que nos leva a inferir que se constitui em uma adequação de ações pedagógicas baseadas na temática central.

A fala da professora B evidencia não existir articulação entre o discurso da coordenação pedagógica e a prática das professoras nas turmas da EJA, nem entre os próprios docentes, explicitando que estes trabalham com as diretrizes educacionais da Secretaria de Educação estabelecidas para a EJA regular.

Eu só vou poder falar do meu trabalho. É porque cada professor tem o seu. E, e também tem esse grupo, por exemplo, que trabalha com 3a, 4a etapa, ensino médio, que quem diz como é que eles vão trabalhar são essas diretrizes lá, essas orientações da coordenação de Educação de Jovens e Adultos da SEDUC, eles é que vão te dizer, porque eles é que sabem, eles é que dizem o que é pra gente fazer (PROFESSORA B).

Com isso, há a tendência de se manter um ensino conteudista. Todavia a professora B, além da preocupação com os conteúdos escolares, busca desenvolver um trabalho de reflexão crítica com as mulheres sobre sua situação de vida social.

o que eu sei é que, eu trabalho com história de vida, eu trabalho com interpretação de texto, eu trabalho com reflexão sobre quando foi, em que momento foi, porque que eles deixaram, porque que elas deixaram de estudar, porque que eles deixaram de estudar, o quê que aconteceu na vida deles pra eles deixarem de estudar, que é pra ver se eles conseguem levar essa informação e, e, é...refletir sobre isso já pensando na criação dos filhos, na possibilidade de evitar ou de tomar mais cuidado em relação, a tentar pelo menos né, em relação à educação dos filhos, o quanto que foi determinante o fato deles serem trabalhadores, deles deixarem a escola, o quanto que isso afastou eles realmente de uma...ou, ou, ou conduziu pra marginalidade, que facilitou, é, potencializou esse caminho pra marginalidade. Então, aqui eles têm o mínimo de conteúdos necessários pra ir pra 3a etapa, saibam ler, interpretar, interpretar gráfico, é, interpretar texto, apresentar um trabalho em grupo, saber que é importante trabalhar em grupo, se perceber como sujeito de direito né, saber que a educação é um direito, que o trabalho é um direito, que o erro é pago, o

Periódico Horizontes - USF - Itatiba, SP - Brasil - e020060 
erro é, o crime, o delito, tá sendo pago aqui, então eles precisam buscar outras, outras possibilidades pra não voltarem, mas pra cá, a autoestima, eu acho que a autoestima, eu acho não, eu tenho certeza, eles chegam aqui muito, são muitos anos sem estudar, e a autoestima perceber que conseguem dominar o conteúdo, conseguem escrever, conseguem retomar a vida e isso é fundamental. (PROFESSORA B).

Há por parte das professoras um trabalho específico com as questões femininas. Por meio da figura 2, a seguir, a professora B problematiza a situação da mulher como objeto de dominação sexual do homem. Discute também os papéis sociais entre homem e mulher na sociedade contemporânea.

Figura 2 - Figura utilizada em sala de aula

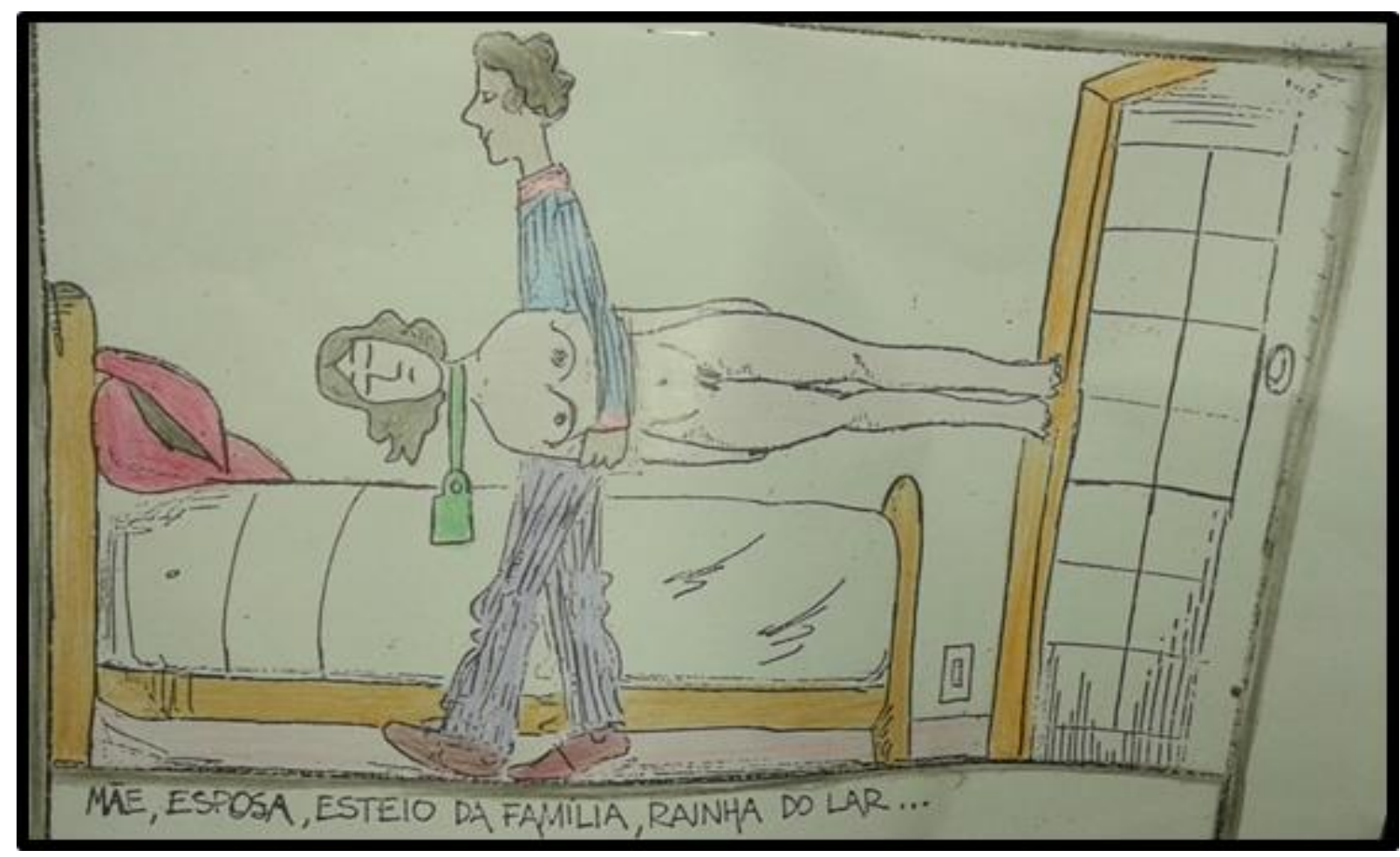

Fonte: Oliveira (2017, p.171)

A professora B no debate sobre a questão de gênero destaca a importância da educação e das mulheres saírem da condição de vítimas para assumirem outras formas de comportamentos sociais, assumindo-se como sujeitos de suas histórias de vida, com vistas a superar as diferenças sociais (OLIVEIRA, 2017). Fato que evidencia uma preocupação com uma educação crítica e engajada politicamente com o contexto sociocultural das mulheres em 
privação de liberdade.

Para Freire (2000, p.42) “a leitura crítica do mundo é um quefazer pedagógico-político indicotomizável do que fazer político-pedagógico, isto é, da ação política que envolve a organização dos grupos e das classes populares para intervir na reinvenção da sociedade".

A professora B ressalta que traz para debate filmes, figuras e textos ilustrados para ajudar na reflexão das educandas sobre a situação da mulher, para que "não desistam e reflitam sobre a vida delas". Afirma como resultado destas discussões sobre a situação das mulheres:

tem uma senhora que dizia assim: 'eu apanhava do meu marido, uma vez ele me tirou sangue, eu não denunciava porque eu tinha medo, ele me ameaçava. Mas se fosse hoje eu ia denunciar!' Então, são coisas assim, que eu vejo que o trabalho avança, suscita esse debate com elas.

A metodologia de ensino adotada pela professora B leva-nos a compreender que a teoria presente em sua práxis se volta para a perspectiva freireana de educação. As histórias de vida, mais que elemento metodológico, sugerem para estas mulheres possibilidades de reflexão crítica acerca de sua realidade e condição de oprimidas frente sua trajetória social e, agora, no momento em cárcere, buscam formas de emancipação, autonomia, liberdade de expressão, repensando os caminhos que as levaram a criminalidade e, os caminhos que as podem levar à libertação, por meio da educação. Sobre essa questão Freire $(2005$, p.45) ressalta:

[...] é importante preparar o homem [e a mulher] para isso por meio de uma educação autêntica: uma educação que liberte, que não adapte, domestique ou subjugue. Isto obriga a uma revisão total e profunda dos sistemas tradicionais de educação, dos programas e dos métodos.

Neste sentido, Freire (2005) destaca que a realidade só pode ser modificada quando o ser humano descobre que é modificável, portanto, umas das formas de se fazer essa descoberta encontra-se na educação enquanto processo de transformação/conscientização dos sujeitos.

Uma educação libertadora sugere instigar os sujeitos da aprendizagem a tomarem consciência de sua existência no mundo, tomar conhecimento de que a educação mais que um direito é uma forma de se rebelar contra as contradições do sistema. É preciso, portanto, como afirma o autor, fazer desta conscientização o primeiro objetivo de toda educação, provocando 
antes de tudo uma atitude crítica e de reflexão, que resulte na ação humana enquanto agente de mudança.

As egressas do sistema penitenciário entrevistadas corroboram a diversidade de estratégias utilizadas, para além dos conteúdos escolares e a preocupação com a formação humanista e crítica das mulheres em privação de liberdade.

Tinha atividade que era feita no quadro, tinha atividade que a gente fazia com cinema, passava um vídeo, tinha ginástica na sala de aula, entendeu? Tinha um dia de ginástica, tinha palestra, entendeu? Então, era diversificado assim, nunca era só aquele negócio de há! Só estudar não, só o quadro e papel. A gente [...] fazia as lembranças do dia das mães [...] da Páscoa, todas essas datas comemorativas a gente sempre acabava fazendo alguma atividade (EGRESSA, A).

Tinha bastante trabalho, a gente fazia trabalho assim em equipe, a gente fazia festinha assim para encerrar o ano letivo [...]. Eles passavam filme para gente, tinha o dia que ele passava ofilme aí depois ele passava uma redação para gente explicar sobre o filme. Essa parte de educação eu não tenho o que me queixar de lá. (EGRESSA, B).

Tinham outros projetos, mas eu não cheguei a participar, mas tinha vídeos [...]. Tinha coral lá dentro, tinha teatro. (EGRESSA, C).

Os conteúdos trabalhados nas turmas de EJA prisional, segundo a Coordenadora A eram selecionados com base na Matriz Curricular dos Parâmetros Nacionais e o que diferenciava era a metodologia, que tinha por base a vivência e as experiências das educandas, indicando existir uma prática dialógica.

Freire (1993b, p.100) destaca que "a escola democrática não apenas deve estar permanentemente aberta à realidade contextual de seus alunos, para melhor compreendê-los, para melhor exercer a sua prática docente, mas também disposta a aprender em suas relações com o contexto concreto".

As egressas confirmam a existência de uma prática dialógica no trabalho dos docentes do sistema prisional com o objetivo delas mudarem de vida.

Ele falava assim que era para gente estudar, para gente ser assim alguém na vida da gente, aí explicava um monte de coisa eles os professores (EGRESSA, B).

Periódico Horizontes - USF - Itatiba, SP - Brasil - e020060 
Eles tinham sim essa autoestima, eles trabalhavam muito isso com a gente. Eles conversavam muito comigo, tinha dias que eu estava atribulada como diz assim lá, aborrecida lá e tal ai 'Não fica assim!' (EGRESSA, C).

A docência no cárcere é vista pelas educadoras com muitas dificuldades e desafios. A Professora B destaca entre as dificuldades materiais: a falta de merenda, de materiais didáticos, de remédios, entre outros, que contribuem para que as mulheres fiquem desestimuladas em frequentar a escola.

A Coordenadora A explica que:

Para mim o maior desafio, é quando eu converso nos meus atendimentos individuais aqui, ou mesmo em coletivo com as nossas reeducandas, e, eu ouço delas: 'há! Eu não quero estudar', para mim é um desafio trabalhar no convencimento, na reconstrução e descobrir o porquê que esta pessoa, a escola para ela é algo tão distante, algo tão abstrato, é algo que ela não consegue conceber a ideia de vir para os nossos espaços de educação. Então, a falta de material de logística, material escolar, material de infraestrutura, para mim, não é assim um desafio mais importante. O desafio que para mim é mais importante, é quando eu converso e elas dizem 'eu não quero estudar!', para mim esse é o desafio maior. Ouvir e trabalhar, desconstruir toda aquela ideia (COORDENADORA, A).

O maior desafio para esta Coordenadora é convencer as educandas voltarem a estudar na escola prisional, que supera as dificuldades em termos materiais, e evidencia uma preocupação de caráter humanista com as educandas, na perspectiva de sua formação escolar.

Assim, apesar das dificuldades e desafios, a educação no cárcere recebida no Centro de Reeducação é considerada muito importante, principalmente, pela possibilidade de serem alfabetizadas e terem um bom aprendizado.

A questão da educação é muito importante sim! Até porque, como eu estou falando, tem muitas pessoas que tão lá, que não sabem nem escrever o seu nome! Entende? [...] Porque tem muitas pessoas que assinavam, faziam a sua assinatura só com um dedo e, que a partir daí, já desse momento da alfabetização, lá de ter a oportunidade de ir para escola já aprenderam a, pelo menos, assinar o seu nome (EGRESSA A).

A egressa B destacou ser importante a escolarização na prisão, porque as detentas, por não saberem ler nem escrever, quando são presas assinam papéis na delegacia sem saber o que 
assinaram e a egressa B informou que muitas saíram da prisão alfabetizadas e com um bom aprendizado.

A educação crítica e dialógica, então, é essencial para a transformação pessoal e consequentemente à reinserção das mulheres privadas de liberdade na sociedade, com tomadas conscientes do ponto de vista ético e político de decisões.

\section{Considerações finais}

O estudo aponta que a docência realizada em turma de Educação de Jovens, Adultos e Idosos em cárcere feminino envolve o enfrentamento de situações de gênero, classe, etnia, idade, entre outras, considerando que o sistema, a cultura e as práticas prisionais tem como modelo o masculino, sendo a mulher secundarizada em sua especificidade feminina, entre as quais, os cuidados maternos com os filhos e a higiene pessoal. No cárcere encontram-se predominantemente mulheres negras, jovens e de baixa escolarização, com filhos, mesmo na situação de solteiras. A maioria está presa porque serviram de transportadoras de drogas para atender aos maridos. Além disso, nem todas frequentam a escola prisional.

É neste contexto que as professoras e coordenadoras pedagógicas trabalham nas escolas do cárcere, com dificuldades de recursos didáticos, e assumindo os desafios de incluir as mulheres em privação de liberdade no convívio social, conscientes de que a educação é um processo fundamental.

Há por parte das educadoras uma preocupação com a formação humanista e crítica das educandas, mesmo sendo observadas contradições nas falas das coordenadoras e professoras sobre a concepção de educação adotada na docência no cárcere, bem como não há participação dos professores na escolha do tema gerador que evidencia a falta de maior envolvimento dos docentes no plano de trabalho da escola do cárcere em estudo.

Na prática pedagógica são desenvolvidos projetos pedagógicos diversos e estratégias, que focam o debate crítico nas diferentes situações de vida das mulheres, entre as quais: a violência contra a mulher, o machismo, as diferenças por questão étnica racial, a desigualdade de classe social e a necessidade da escolarização para a mudança de status social.

Nesta perspectiva, há por parte das educadoras a compreensão da necessidade no 
cárcere feminino de uma educação humanista, dialógica e crítica, que possibilite o empoderamento das mulheres nas tomadas de decisões em sociedade, sendo sujeito de seu conhecimento e história de vida. Uma educação engajada politicamente que não reproduza o discurso histórico de submissão das mulheres na sociedade.

Apesar deste Centro de Reeducação ter vínculo com uma Unidade Materna Infantil de atendimento às mulheres grávidas e em processo de aleitamento, muito se precisa ainda avançar na organização e nas práticas prisionais para superar a cultura machista e atender de fato e de direito as demandas das mulheres, tendo a docência no sistema prisional um papel fundamental de conscientização crítica e de denúncia das situações de opressões vivenciadas pelas mulheres na sociedade e no cárcere.

\section{Referências}

AILANDA, J. A situação das mulheres no cárcere. Jusbrasil. 2017. Disponível em: https://jessicaailanda.jusbrasil.com.br/artigos/607724070/a-situacao-das-mulheres-nocarcere. Acesso em: 05 jan. 2020.

BARDIN, L. Análise do conteúdo. Lisboa: Edições 70, 1979.

BRASIL. Educando para a liberdade: trajetória, debates e proposições de um projeto para a educação nas prisões brasileiras. Brasília: UNESCO, MEC, MJ, 2006.

BRASIL. Ministério da Educação. Documento nacional preparatório à VI Conferência Internacional de Educação de Adultos - VI CONFINTEA. Brasília: MEC; Goiânia: FUNAPE/UFG, 2009.

COLARES, L., CHIES, L.A.B. Mulheres nas so(m)bras: Invisibilidade, reciclagem e dominação viril em presídios masculinamente mistos. Estudos Feministas, v.18, n.2, 407-423, maio-ago. 2010.

FREIRE, P. Pedagogia do oprimido. 11.ed. Rio de Janeiro: Paz e Terra, 1987.

FREIRE, P. Pedagogia da esperança: um reencontro com a pedagogia do oprimido. 2.ed. Rio de Janeiro: Paz e Terra, 1993a.

FREIRE, P. Professora sim, tia não: cartas a quem ousa ensinar. 2.ed. São Paulo: Olho D’Água, $1993 b$

FREIRE, P. Pedagogia da indignação: cartas pedagógicas e outros escritos. São Paulo: UNESP, 2000. 
FREIRE, P. Conscientização: teoria e prática da libertação: uma introdução ao pensamento de Paulo Freire. 3.ed. São Paulo: Centauro, 2005.

GOFFMAN, E. Manicômios, prisões e conventos. São Paulo: Perspectiva, 1961.

LUDKE, M.; ANDRÉ, M. A Pesquisa em educação: abordagens qualitativas. 2.ed. São Paulo: E.P.U., 1986.

MENDES, S. R. Criminologia feminista: novos paradigmas. São Paulo: Saraiva, 2014.

MERELES, C. Brasil e sua população carcerária. Politize!, 01 de março de 2017. Disponível em: https://www.politize.com.br/populacao-carceraria-brasileira-perfil/. Acesso em: 05 jan. 2020.

OLIVEIRA, I. A.; MOTA NETO, J. C. Construção de categorias de análise na pesquisa em educação. In: MARCONDES, M. I.; OLIVEIRA, I. A.; TEIXEIRA, E. (orgs.). Abordagens teóricas e construções metodológicas na pesquisa em educação. Belém: EDUEPA, 2011, p.161-179.

OLIVEIRA, S. S. Educação no cárcere: processo de reinserção social de mulheres. 2017. 264f. Dissertação (Mestrado em Educação) - Programa de Pós-Graduação em Educação da Universidade do Estado do Pará - PPGED-UEPA, Belém, 2017.

PEREIRA, A. A educação-pedagogia no cárcere, no contexto da pedagogia social: definições conceituais e epistemológicas. Rev. Ed. Popular, Uberlândia, v.10, p.38-55, jan./dez. 2011.

PONTES, F.; MARTINS, H. População carcerária feminina cresce $700 \%$ em dezesseis anos no Brasil. Agência Brasil, 26 de agosto de 2017. Disponível em: https://noticias.uol.com.br/cotidiano/ultimas noticias/2017/08/26/populacao-carcerariafeminina-cresce-700-em-dezesseis-anos-no brasil.htm. Acesso em: 05 jan. 2020

V CONFERÊNCIA Internacional sobre Educação de Adultos - CONFINTEA. Declaração de Hamburgo sobre Educação de Adultos. Hamburgo, Alemanha, julho de 1997. Disponível em: http://forumeja.org.br/pi/sites/forumeja.org.br.pi/files/V\%20Confintea\%20Hamburgo\%201997 .pdf. Acesso em: 03 jan. 2020.

VASQUEZ, E. L. Sociedade cativa entre cultura escolar e cultura prisional: uma incursão pela ciência penitenciária. 2008. 163f. Dissertação (Mestrado em História da Ciência) - Pontifícia Universidade Católica de São Paulo, São Paulo, 2008.

Recebido em janeiro 2020.

Aprovado em julho 2020. 